\title{
School Based Reproductive Health Education and Teenage Pregnancy: A Case of Mtwara Region, Tanzania
}

\author{
Hawa Dunor $^{1} \quad$ Justin K. Urassa ${ }^{2}$ \\ 1.Assistant Director, Adolescent Girls Division, Ministry of Gender Children and Social Protection, Monrovia, \\ Liberia \\ 2.Department of Policy, Planning and Management, Sokoine University of Agriculture, P.O. Box 3035, \\ Morogoro, Tanzania
}

\begin{abstract}
Teenage pregnancy is one of the complex health and development problems facing the world. In Tanzania adolescent pregnancy has been identified as one of the reasons for girls dropping out of school. The purpose of this study was to determine the effectiveness of school based reproductive health education programmes on teenage pregnancy. The study adopted a cross-sectional explanatory design and was conducted in Mtwara Region, Tanzania covering four secondary schools. Respondents for the study were randomly selected. Data was collected using a pre-structured questionnaire, focus groups discussions and key informant interviews. A total of 156 individuals participated in the study. Findings from the study show that school based reproductive health education programmes were effective in terms of knowledge creation. Generally, the results show a significant $(\mathrm{P} \leq 0.001)$ difference in reproductive health education between intervention and non-interventions schools. In addition, significant differences were also observed between rural and urban non-intervention schools. It is therefore concluded that school based reproductive health education programmes are effective in knowledge creation among adolescent girls. Hence, it is recommended that a comprehensive school based reproductive health education programme (SBRHEP) be instituted in schools as a way of reducing teenage pregnancies and spread of sexually transmitted diseases (STI's). However, for this to be more effective there is need for a standalone subject that only deals with reproductive health education rather than the status quo where it is offered under the biology subject.
\end{abstract}

Keywords: School based Reproductive health education, Teenage pregnancy

DOI: $10.7176 / \mathrm{DCS} / 9-1-03$

\section{Introduction}

Teenage pregnancy is one of the many development and health challenges facing Tanzania. According to the Tanzania Demographic Health Survey TDHS (URT, 2010) nationally, 23\% of women aged 15-19 have started bearing children while $44 \%$ of them are either mothers or pregnant with their first child by the age of 19 years. As girls enter adolescence, the risk of pregnancy becomes a major factor leading to school dropout posing a serious challenge to the mother, the child and the society at large. Teenage pregnancy has now become an alarming and complex worldwide medical and social problem that is closely linked to psychological, educational; social economical, cultural, and political factors (Siettou and Sarid, 2011). Moreover, teenage mothers are likely to be unmarried, poor and are most likely to drop out of school hence, compromising their future prospects of being employed high in skilled jobs requiring post secondary school education.

Tanzania, like many other developing countries is vulnerable to the problem of teen pregnancy. According to the Center for Reproductive Rights (2013), between 2003 and 2011 over 55000 teenage girls dropped from both primary and secondary schools due to pregnancy. The Tanzanian government and development partners have made efforts in reducing teenage pregnancy by initiating programmes and policies to reduce the same. These initiatives have come in the form of reproductive health education taught in both primary and secondary schools and by sponsoring media campaigns with a variety of messages aimed at promoting teen pregnancy prevention, introduction of youth friendly services at health centres, to mention a few (Kessler, 2009; Dunor, 2015). An example of media campaigns include the Fema magazine, Si Mchezo, Ruka Juu and the Fema Radio Programme: all these focus of creating awareness among young people about their reproductive health and rights (Femina, 2013).

Despite the above mentioned efforts, teenage pregnancy remains one of the major social problems facing Tanzania today. Data from the World Health Statistics (WHS) (2013) shows Tanzania to be among the developing countries with high rates of teenage pregnancy in the world. Although, school based reproductive health education programmes (SBRHEP) are run in the study area (Mtwara Region), teenage pregnancy is high despite implementation of the mentioned programmes. According to a study conducted in Mtwara by Mbeba et al. (2012), it was found that adolescent girls were highly exposed to the risk of early pregnancy, sexually transmitted infections (STI) and HIV/AIDS infections; with the initiation of sexual activities at the early age of 9 to 10 years. Therefore, the current study aimed at determining the impact of school based sexual and reproductive health programmes (SBRHEP). Generally, there is a lack of sufficient information on their 
effectiveness. For example studies by Makundi (2010), Ewald (2008) and Nyakubega (2009) and others on the subject have focused more on the factors that cause teenage pregnancy and contraceptive use rather than intervention and prevention: thus, creating the gap that prompted the current study. Basically, the study aimed at analyzing the contribution of SBRHEP to reduction of teenage pregnancy in Mtwara Region, Tanzania. The study also aimed at answering the following questions, what are the socio-economic factors responsible for teenage pregnancy in the study area? How accessible is reproductive health education to teenage girls in Mtwara Region? Are the current school based pregnancy prevention programmes comprehensive? Why is teen pregnancy in Mtwara Region still high amidst several intervention programmes? And what are the methods used by reproductive health education providers in secondary schools in Mtwara Region. In addition, the study aimed at testing the hypothesis that there were no significant differences in relation to sexual and reproductive health knowledge between the intervention and non-intervention groups/schools.

\section{Research Methodology \\ 2.1 Study Design}

The study adopted a cross-sectional research design whereby data were collected at one point in time (Bob and Liz, 2010). Generally, the design is useful for descriptive purposes as well as for determination of relationships between and among variables. In addition, the study used a mixed method approach in data collection whereby both quantitative and qualitative data were collected. According to literature (Kanire, 2012) a mixed methods approach allows one the possibility of triangulation which enables one to use various methods to validate and check the results. Of great importance is the fact that the use of different methods allows one to verify, validate and minimize the weaknesses caused by any of the methods if used alone.

\subsection{Study's population, sampling technique and sample size}

The study's population included all female students in Mtwara secondary schools. Due to time constraints two local government authorities were purposefully selected for the study, these were Mtwara Municipality (Urban) and Mtwara District (Rural), the two were selected to allow for comparison between students in urban areas and those in rural areas based on the assumption that sharing and access to information differs between the two with the urban areas being more accessible. After the above was done two schools were randomly chosen from the two clusters of intervention and non-intervention schools: the intervention schools are those in which Prevention and Awareness in School HIV and AIDS Peer Education (PASHA) programme had been implemented. Therefore, schools involved in the study were four i.e. two intervention ones (Mtwara Girls Secondary School (Urban) and Nanyamba Secondary School (Rural) and the two non-intervention ones i.e. Chuno Secondary School (Urban) and Ziwani Secondary School (Rural)).

The sampling frame for the study was students from the above-mentioned secondary schools. The sample size was 104 respondents. According to Sunder (2007), a sample size intensity of 30 households could be considered for any research. Additionally, Warren (2002) also suggests that, the minimum requirement for sample size in qualitative studies needs to be between 20 and 30 in order for an interview-based qualitative study to be published. Therefore, based on the above, 52 students were randomly drawn from both the intervention schools and non-intervention ones. Random sampling was seen to be appropriate as it allows an equal opportunity for all elements in the sampling frame to be included in the final sample. In addition to the above, snowball sampling was employed to identify adolescent girls who had dropped out of school because of pregnancy: these served as key informants along with other key informants i.e. teachers, health workers and parents. The later were purposefully selected as were they assumed to be knowledgeable on the study subject. Generally, information collected from the key informants focused on teenage students' pregnancy prevalence rates, causes of teen pregnancy and the impact of it on the region's development.

\subsection{Data Collection}

Both qualitative and quantitative data types were used; this was based on the importance of triangulation in social science studies. Triangulation is a combination of two or more methodological approaches, theoretical perspectives, data sources, investigators and analysis to study the same phenomenon for the purpose of increasing a study's credibility (Hussein, 2009). Generally, primary data were obtained using a questionnaire, focus group discussions (FGDs) and Key Informant Interviews (KIIs). The FGDs and KIIs involved students, teachers of sex education subjects, health workers, school dropouts and parents in the study area. The FGDs and KIIs were guided by an FGD guide and a check list respectively. Through the FGDs and KIIs in-depth qualitative information was collected to complement the data collected from the respondents using a prestructured questionnaire. Before the actual survey, a pilot study was conducted in order to ensure that the questionnaire was valid and reliable. Testing of the research tools was done to ensure clarity and familiarity with the tools as well as the study area. Data was generally collected from a total of 156 individuals as detailed in Table 1. However, data from the students involved in the pre-testing of the information collection tools is not 
included in the final analysis. The pre-testing was done with 19 students from two secondary schools namely Umoja and Nanguruwe Secondary Schools in Mtwara District and urban Mtwara Municipality respectively

Table 1: Data collection details

\begin{tabular}{|c|c|c|}
\hline Activity & Area/Group Involved & $\begin{array}{c}\text { Number of individuals } \\
\text { involved }\end{array}$ \\
\hline $\begin{array}{l}\text { Pretesting of data } \\
\text { collection tools }\end{array}$ & $\begin{array}{l}\text { Umoja and Nanguruwe secondary schools found in } \\
\text { Mtwara District }\end{array}$ & 19 \\
\hline Actual data collection & $\begin{array}{l}\text { Intervention schools (Mtwara Girls Secondary } \\
\text { School-Urban and Nanyamba Secondary School- } \\
\text { Rural) } \\
\text { Non-intervention school (Chuno Secondary School } \\
\text { - Urban and Ziwani Secondary School-Rural) }\end{array}$ & 52 \\
\hline $\begin{array}{l}\text { Focus group } \\
\text { discussions } \\
(\text { FGDs)(four in total) }\end{array}$ & $\begin{array}{l}\text { Students (nine participants per group) (18 } \\
\text { intervention schools and } 18 \text { the Non-intervention } \\
\text { schools) }\end{array}$ & 36 \\
\hline Key informants & $\begin{array}{l}\text { School drop outs } \\
\text { School teachers teaching sex education/biology } \\
\text { Health workers } \\
\text { Parents }\end{array}$ & $\begin{array}{l}5 \\
4 \\
4 \\
3\end{array}$ \\
\hline
\end{tabular}

\subsection{Data Analysis}

Generally, the quantitative data collected through the pre-structured questionnaire were coded and analyzed using the Statistical Package for Social Sciences (SPSS) software. The data were analyzed using the nonparametric analysis known as the Independent Mann Whitney U-Test. The above was used to determine the effectiveness of SBRHEPs among students in terms of knowledge. In addition, the Mann Whitney U-Test was used to compare the difference in knowledge on reproductive health and teenage pregnancy prevention between girls from PASHA schools relative to the non-intervention ones. This test was chosen because the results obtained from the test scores were not normally distributed and therefore did not meet the assumptions of using a parametric test specifically Independent Samples T-test (DeCoster, 2006: 6). As regards qualitative data collected through the FGDs and KIIs these were analyzed using content analysis. This method is useful for identifying general themes, intentions, focus of communication trends of an individual, group or organization (Busch et al., 2012).

\section{Results and Discussions}

\subsection{Content of Sex Education Teaching in the Study Area}

One of the study's specific objective was to assess the content of school based sex education this mainly aimed at determining how the content of the SBRHEP could help reduce teenage pregnancy among secondary school girls. Generally, observations from the study show that the focus of the teachings has mainly been on abstinence with little attention being paid on use of contraceptives. Almost all (92\%) of the respondents stated that the information they got was on abstinence. A study on teen pregnancy by Culp- Ressler (2013) observed that the high rate of teen pregnancy in rural America was a result of clinging to abstinence only curricula that does not give teens enough information about pregnancy preventive methods. Generally, it is argued that comprehensive sex education, or abstinence-plus programmes can achieve positive behavioural changes among young people thereby, reducing STIs (Sexually Transmitted Diseases) compared to abstinence only programmes (Collins et al., 2002). According to Collins et al., abstinence plus programmes do not encourage young people to initiate sexual activity earlier or have more sexual partners as generally perceived by people but, only expand the available options to pregnancy prevention. Collins et al. further argue that whether or not young people are sexually active, they should be given all the necessary information to enable them protect themselves from unplanned pregnancies and sexually transmitted diseases. Abstinence-only programming runs the serious risk of leaving young people, especially those at an elevated risk, uninformed and alienated. The above is supported by de Haas et al. (2017). de Haas et al. citing literature points out that there is a debate on whether sexuality education should focus exclusively on promoting abstinence or whether programmes should be more comprehensive. Whereas abstinence-only sexuality education programmes usually promote sexuality education based on moral teachings, more comprehensive programmes see young people/adolescents'/teenagers as active sexual agents who need to be well-informed based on hard evidence so as to enable them make the right choices with regard to their sexual and reproductive health and rights.

Further to the above, Kirby et al. (2005), argues that some sex education programmes make measurable differences in the lives of young people. Normally, the negative consequences of teen sexual activity are complex and not easily remedied with a school class or an after school programmes. According to Kirby et al., 
teen sexuality is influenced by parents, schools, communities, the media, society as whole, available prevention technology, and individual young people themselves. However, for Tanzania, the growing prominence of the abstinence-only approach will likely have serious unintended consequences by denying young people access to the information they need to protect themselves. For example, Tanzania's Education Department prohibits condom promotion and demonstrations in schools and demands a focus on abstinence, a strategy that has been shown to be ineffective (Underhill et al., 2007). According to Underhill et al., the reasons for sticking to abstinence only teachings can partly be attributed to cultural and religious views of what should be discussed with teens. The above is echoed by observations from the FGDs and key informants, whereby FGDs participants and Key informants (KI) had different views about the "sex education" they receive in school. For example, some FGD participants found it 'too biological' i.e. lacking practical information about how to protect themselves from unintended pregnancies and STIs. However, almost all the key informants interviewed supported the teaching of SRH education. Nevertheless, some were skeptical about discussing sensitive issues such as sex with teens. The mixed arguments are shown in the quotes below:

"I would like my child to learn how to take care of herself, but I would not want her to know everything about sex before she begins to try out. You know children are very sensitive" (A 49 year old female KI, Mtwara Municipality, October 20, 2014).

"For me, teaching children adult things is what is making the world the way it is now. Children know everything about sex so they give no respect to adults because they have learnt about sex at school" (A 53 year old male KI, Mtwara District, October 24, 2014).

"I am not against teaching of reproductive health or in favour of teaching it to the students. However, as long as they learn how to prevent pregnancy and HIV, I think it should be taught to them" (A 37 year old female KI, Mtwara District October 27, 2014).

"I think teaching sex education at school is a good idea because most parents or guardians do not feel free talking about sex related issues with their children. Therefore, if the teachers can do so, then they are helping us and I think it will help reduce teenage pregnancy too"(A 35 year old male KI, Mtwara Municipality, October 21, 2014).

"Nowadays school is where they learn all their bad behaviours because of the sexual teaching they are getting”. Everything is exposed to them (A 50 year old KI (Mother), Mtwara District, October 27, 2014).

"For me I do not know what difference teaching reproductive health education will make because these days, the girls go to school to study pregnancy and the result is a child" (A 42 year old female KI, Mtwara Municipality, October 27, 2014).

Based on the above quotes one can clearly see the divide that exists in the research area in relation to teaching of SRH in schools. Therefore, reduction of teenage students' pregnancy rates can only be a success if more awareness and empowerment of parents and guardians is provided. In addition, teenage pregnancies in Tanzania and other parts of Africa can easily be prevented if parents and/or guardians come to terms with reality. Currently, many girls and boys engage more in pre-marital sex compared to the past when this was seen as a taboo: in the past sex encounters were only allowed after marriage either legally (i.e. by authorized clergy/religious leaders and of public servants-District Commissioner's office) or customarily/clan norms.

\subsection{Sources of Information on Sexuality Education}

In order to know the contribution of SBRHEP, the respondents were asked to identify their major sources of information on sexual reproductive health $(\mathrm{SRH})$ and teenage pregnancy prevention. Results on the above are summarized in Table 2. Generally, study findings show that peers and friends were the most reliable source of SRH knowledge for adolescents in both Mtwara District and Mtwara Municipality. This was reported by about three quarters $(72 \%)$ of the respondents. According to the respondents the above normally happens during evening hours when teenagers meet to discuss issues largely around their romantic and sexual encounters. Therefore, through their networks the youth come to know about the sexual activities of their peers, contraception information, SRH service accessibility, among other things. The observations are also supported by those from the KIIs and FGD participants as shown in the quotes below:

"Girls, during evening hours, usually gather in groups and discuss issues pertaining to boyfriends and their friends. That is the business they are good at doing” (A 37 year old female KI, Mtwara Municipality, October 18, 2014).

"I feel free discussing with my friends especially my best friends. I can tell them who I am dating, when I am hurt and even when I am sick. My best friend is the first person I normally tell" (A 16 year old FGD participant, Mtwara District, October 27, 2014).

According to a study by Planned Parenthood (2012), it was found that half $(50 \%)$ of all teens feel uncomfortable talking with their parents about sex. It was further reported that teens feel comfortable discussing issues of sexuality more with their peers than with others who are not in their circles. According to Imron (2014), adolescents are more comfortable and open to discuss matters pertaining to reproductive health with their peers 
because they considered them to have an emotional closeness, equal knowledge level and being in common culture or social solidarity whereby one's problem is also the others'. Imron further argues that, the comfortability of adolescents discussing SRH issues with peers who are usually not knowledgeable enough on the subject often results into getting the wrong information. Observation from the study show that, in Mtwara, peer networks and friends were the biggest source of SRH knowledge among teenagers hence; misconceptions especially about the use of condoms are common in both Mtwara Municipality and Mtwara District. Evidence to this is shown in the quotes below:

"The oil that is in the condoms is not good; it smells bad and causes infection" (A 16 year old FGD participant, Mtwara District, October 29, 2014).

"Condoms have tiny holes through which sperm passes, so what is the need of using it. I have seen the holes, my friend showed them to me" (A 15 year old FGD participant, Mtwara Municipality, October 22, 2014).

Table 2: Major sources of sexuality and reproductive health (SRH) information $(n=104)$

\begin{tabular}{lrr}
\hline Major sources of SRH information & Frequency & Percent \\
\hline Friends & 75 & 72.1 \\
School & 50 & 48.1 \\
Parents & 49 & 45.2 \\
Radio & 37 & 35.6 \\
Magazines & 32 & 30.8 \\
Television (TV) & 28 & 26.9 \\
Newspaper & 14 & 13.5 \\
Health facilities & 13 & 12.5 \\
Home & 12 & 11.5 \\
Street & 10 & 9.6 \\
Religious institutions & 7 & 6.7 \\
Workshops & 4 & 3.8 \\
Books & 4 & 3.8 \\
Village meeting & 3 & 2.9 \\
\hline
\end{tabular}

NB: Due to multiple responses, the responses gathered are greater than the sample of 104

The results in Table 2 further show that parents were another important source of information as mentioned by over two fifths $(45.2 \%)$ of the respondents. However, though the results show that parents are an important source of SRH children nonetheless don not feel comfortable doing so (Planned Parenthood, 2012; Healy, 2012). However, more direct communication between mothers and daughters was not noted, although for most of the respondents such communication was usually initiated only after the daughter became pregnant or had given birth. In most cases where the parents themselves did not communicate with their children, use of a third person was very common. Aunties were also considered as parents who often spoke to young girls about important SRH topics as shown in the quotes below:

"My mother's friend is the person that tells me how to prevent myself from pregnancy, but my mother only gets angry with me every time; she does not tell me anything although she wants me to know things" ( A 16 year old FGD participant, Mtwara Municipality, October 25, 2014).

"I do not discus SRH issues with my mother and she too does not. I don't know why" (A 15 year old respondent, Mtwara District, October 28, 2014).

The study's finding is in line with what has been reported by Phetla et al. (2008) that, women who were part of a multifaceted intervention were more likely than those who were not to report communication with their children and other members of their household about issues related to sex and condom use, rather than just about the dangers of sex. The results are also comparable with those of Adu-Mireku (2003) who found that schoolgoing youth who reported parent-child communications about HIV/AIDS were more likely to have used condoms at last sex, but communication was not associated with onset of sexual activity. Similar findings were reported by Kawai (2008) who found that $27 \%$ of $12-14$ - year-old virgins in Tanzania were reported to have talked with their parents about sex and HIV, but these discussions were not associated with the timing of sexual initiation.

Observation from the study (Table 2) also show that in both Mtwara District and Mtwara Municipality, schools are a major source of SRH knowledge which indicates that sexual education at school seems to be influential in the region and in improving sexual reproductive health of the girls. If properly utilized through effective teaching it could be a source of reducing teenage pregnancy. However, as mentioned earlier on factors contributing to teenage pregnancy, lack of education was a major reason mentioned thus, indicating that either the educational potential of schools in terms of SRH is not adequate as most of the teachings are basically on biological and not practical pregnancy prevention or sexual relations. Also this can be attributed to the fact that not much priority has been given to the subject because the course is not taught as a stand-alone subject in the 
schools. Generally, issues of SRH are discussed in biology and life skills sessions/lessons: schools do not have special/separate sessions to teach SRH. The above is supported by the quotes below:

"They usually teach us about our body and the different parts, but they don't tell us anything valuable. Some of the key things we want to know is how do girls get pregnant and how can we prevent it" (A 14 year old respondent, Mtwara District, October 28, 2014).

"The lessons we are getting are not enough. The time is short and we do not talk about the real sex issues" (A 15 year old respondent, Mtwara Municipality, October 24, 2014).

"The topics on SRH that we are teaching to the students are relevant to them because if one knows how to prevent herself from getting HIV and other STI, then they are able to prevent pregnancy as well. We are teaching them about life skills and refusal too" (A 34 year old female KI, Mtwara Municipality, November 1, 2014).

"Nowadays, schools are teaching children about their bodies and puberty, but they give this information when the children are not mature enough to understand it, so it doesn't help them" (A 45 year old male KI, Mtwara District, 0ctober 27, 2014).

Additionally, adolescents reported learning about SRH from their peers, family, media (such as radio programmmes and magazines), and at school. The research findings show that SRH knowledge is not sought at health facilities very often, which might be due to embarrassment in seeking services among others with conventionally perceived health problems of more gravity. The observation differs from those of a study conducted by Nyakubega (2009) in Tanga, Tanzania, which found that the major sources of reproductive health education $(82.6 \%)$ were from health centres and parents, with schools and peer groups contributing only $29.1 \%$ and $7.2 \%$ respectively. The difference in this observation can partly be attributed to the method used whereby both sources were combined in the author's analysis, which is different from this study's reporting of sources which separates all sources. Based on the above and particularly the last quote one sees that not much has changed since Tumbo-Masambo (1994) concluded in the article 'Too little too late' that information on sexuality and reproductive health is normally offered to girls very late i.e. at or after menarche when a girl may have already fallen pregnant. According to Tumbo-Masambo it is more beneficial if girls would be provided with the above before the first ovulation which normally takes place before menarche.

In addition to the above, various forms of media were reported by more than a quarter of the respondents as their source of SRH information which included the radio followed by magazines and the least was TV. The respondents commended the Fema magazines as being very informative and educative. However, it was observed that most of those magazines seemed to only reach the in-school youth. The finding of this study are comparable to those of a BMRB tracking survey which states that young people aged 13-21years reported their main sources of information about sex and relationships as being lessons at school (81\%), friends (49\%), parents 51 and $20 \%$ for mothers and fathers respectively, magazines, books, posters and newspapers (41\%), and TV and videos (38\%) (BMRB International, 2003).Additionally, adolescents reported learning about SRH from their peers, family, media (such as radio programming and magazine), and at school.

\subsection{Contribution of School Based Sex Education Programme}

To determine the contribution of SBRHEPs, a set of SRH questions were administered to students from the intervention and non-intervention schools. The scores from the test result were calculated in percentage. A nonparametric test (Man Whitney U-Test) was used to compare the score between the groups. The above-mentioned test was used because the scores were not normally distributed based on the count of 1 to 13 . The results (Table 3) show that the median score for the students from intervention schools was 96 whereas the median score for the students from the non-intervention schools was 80 . The difference of the two median scores was statistically significant $(\mathrm{P} \leq 0.001)$ implying that the students from the intervention schools had a relatively higher level of SRH knowledge with regard to how to avoid teenage pregnancy compared to the non-intervention ones. The same Mann Whitney U- Test was also run between urban and rural intervention schools. However, the results show there was no statistically significant $(\mathrm{P} \leq 0.206)$ difference in terms of SRH knowledge between the two groups; their medians were 100 and 92 respectively. However, there was a significant $(\mathrm{P} \leq 0.001)$ difference between the none-intervention urban and rural schools: their medians as 84 and 69 respectively.

Table 3: Comparisons of knowledge test score and Mann Whitney $U$ test results

\begin{tabular}{lrr}
\hline Groups & Median scores & P values \\
\hline Intervention and & 96 & $0.000^{* *}$ \\
None-intervention schools & 80 & 0.206 \\
\hline Urban intervention and & 100 & $0.000^{* *}$ \\
Rural intervention & 92 & 84 \\
\hline Urban none-intervention & 69 & \\
Rural none-intervention & & \\
\hline
\end{tabular}

NB: $* * *$ significant at $\mathrm{p}=0.001$ 
The above findings suggest that both intervention and non-intervention schools were somehow knowledgeable on SRH. Nonetheless, students from intervention schools were relatively more knowledgeable compared to those from the non-intervention schools. The results suggest a positive impact of the SBRHEPs toward improving students' knowledge on avoidance of teenage pregnancy. The finding is comparable to what was reported in a systematic review of school-based sexual health interventions in Sub-Saharan Africa by PaulEbhohimhen et al. (2008). According to the above, school based reproductive health interventions have an impact on improvement of knowledge, attitudes and intentions, however, only little evidence of lasting behavioural changes was observed. Similar results have been reported for a school-based intervention in Thailand. For example, Thato et al. (2008) reported that secondary school students who were exposed to a comprehensive sex education programme had greater knowledge than other students, and were more likely to have protected sex and to decrease frequency of sex. A study in the Dominican Republic showed similar results that adolescents who received sex education had higher rates of condom use and more knowledge of HIV than those who did not (Minaya et al., 2008).

Study results further show that the urban non-intervention students were more knowledgeable on the subject matter than their rural non-intervention counterparts. The reason for this difference could partly be attributed to the urban environment; generally people in urban areas have more access to reproductive health services and other sources of information than their rural colleagues. The above is supported by the quotes below:

"It is difficult to get treatment early when you visit the hospital because there are lots of people to be served and you have to wait for a long time" (A 17 year old FGD participant, Mtwara District, October 29, 2014).

"We have many dispensaries in the municipality; sometimes if you don't want to go to the regional hospital you can just quickly visit a dispensary closer to where you live” (A 15 year old FGD participant, Mtwara Municipality, November 1, 2014).

Additionally, the issue of accessibility to different sources of information with regards to SRH might be one of the factors lacking in the rural areas, making their urban counterparts better off in terms of knowledge. According to Thin Zaw et al. (2012), access to media and other sources of information such as TV, radio, formal and education programmes were found to be helpful in filling the gap of meeting the unmet needs in SRH that could not be given by schools and other service providers. However, these sources of information are most often found in urban areas as compared to rural areas.

Generally, the overall findings on students' knowledge on SRH were encouraging. Most of the respondents demonstrated adequate knowledge on the impact of teenage pregnancy, safe sex, family planning, and the negative consequences of each when not practised. The study observed that knowledge on various contraceptive methods was also relatively high, with condoms, pills and injections being very popular. However, though the respondents proved to have knowledge on contraceptives, observation from the study in relation to students from both Mtwara District and the Municipality show that they had different perceptions about usage of condoms. Specifically, the students from Mtwara District perceived the use of condoms as a sign of prostitution while those from the Municipality asserted that using them does not make sex enjoyable. Below are quotes showing the mixed arguments:

"Once you tell your lover/partner to use a condom he will assume that you have started cheating on him" (A 16 year old FGD participant, Mtwara District, October 28, 2014).

"Using condoms doesn't make sex enjoyable. It is like eating candy with its wrapper on" (A 15 year old FGD participant, Mtwara Municipality October 30, 2014).

"To use condom is a sign of prostitution" (A 15 year old respondent, Mtwara District Council, October $28,2014)$.

Generally, the current study did not observe difference in terms of condoms use between Mtwara Municipality and its rural counterpart, Mtwara District. The lack of difference may be a result of respondents from both districts having some kind of perceived misconception about the use of condoms. The study findings are comparable to Fisseha's (2015) study which was conducted in Ethiopia among young women aged 15 to 24 years. According to the study young women were not using condoms because of misconception of the same not being a reliable or trusted prevention method. Additionally, similar findings of misconception of condoms use among adolescents have also been reported by Knopf et al. (2017). According to Knopf et al. some adolescents/teenagers belief that condoms are contaminated with HIV during manufacturing thus their use may expose them to danger of attracting the diseases which could eventually kill them. In addition, some adolescents/teenagers do also believe that the condoms are too big to be used by them.

\section{Conclusions and Recommendations}

Teenage pregnancy is one of the complex health and development problems facing the world. In Tanzania adolescent pregnancy has been identified as one of the reasons for girls dropping out from school. The purpose of this study was to determine the effectiveness of SBRHEP on teenage pregnancy. Based on the study's results 
it can be concluded that SBRHEPs are effective in knowledge creation among adolescent girls. It is also concluded that differences in knowledge on SRH education differs between schools where the intervention is being applied and those not enjoying the same. It is further concluded a difference in the above also exists between the non-intervention urban and their rural counterparts. It is further concluded that, the content of reproductive health education programmes are not comprehensively taught in secondary schools in the region as the subject is not taught as a standalone one. Moreover, the content of the SBRHEPs is focuses more on HIV/AIDS prevention. Lastly, it can be concluded that although the content of SBRHEPs are not comprehensive nonetheless; the programmes have proven to be effective towards knowledge creation among secondary school students.

Based on the above it is recommended that a comprehensive SBRHEP be instituted in schools as a way of reducing teenage pregnancies and spread of sexually transmitted diseases (STI's) including HIV/AIDS. Doing the above will not only help in students teen pregnancy reduction but also in providing them with the requisite knowledge and skills hence, dealing with the misconceptions generally shared among peers which are detrimental in most cases. In addition, there is need for SRH to be taught as a standalone course/subject and in a more practical manner i.e. SRH needs to be provided in a holistic and comprehensive way thus, it should not be one sided "abstinence only" but needs to also cover use of contraceptives and the need for being faithful to one lover at a time. Doing the above will enhance students' understanding and therefore future use of the knowledge and skills gained. More importantly, there is need for a close collaboration between the ministry of health and that of education if teenage pregnancy is to be reduced amongst secondary school students. For example, the Ministry of Health and Education could collaborate in providing SRH education by allowing Trained Health Practitioners to teach SRH as a standalone subject in schools. Additionally, the Ministry of Education should include and ensure that each school runs a special session for SRH subjects.

\section{Conflict of interest}

The authors of this paper have no competing interest.

\section{Acknowledgements}

The authors will like to acknowledge the support from West Africa Agriculture Productivity project (WAAPP) for proving fund during the course of the research

\section{References}

Adu-Mireku, S. (2003). Family Communication about HIV/AIDS and Sexual Behaviour Among Senior Secondary School Students. African Health Sciences, Accra, Ghana. 14pp.

BMRB (British Market Research Bureau) (2003). Teenage Pregnancy Strategy Evaluation. Presentation of results of Wave 8 14th April 2003.http://www.thensmc.com/sites/ default/files/Teenage $\% 20$ Pregnancy $\% 20$ Strategy $\% 20$ Evaluation $\% 20-\% 20$ Wave $\%$ 208_255668.pdf[30/04/2018]

Bob M and Liz R (2010). Research Methods. A Practical Guide for the Social Sciences. Rotolito Lombarda, Italy. $121 \mathrm{pp}$.

Busch, C., De Maret, P. S., Flynn, T., Kellum, R, Le, S., Meyers, B., Saunders, M., White, R. and Palmquist, M. (2012). Content analysis writing and csu. Colorado State University. [http://writing.colostate.edu/guides.cfm?guideied =61] site visited on20/7/2014.

Center for Reproductive Rights Tanzania (2013). Forced out- mandatory pregnancy testing and expulsion of pregnant students in Tanzania. [www.reproducti verights.org/en/press-room/new] site visited on 28/4/2014.

Collins, C., Alagiri, P. and Summers, T. (2002). Abstinence Only vs. Comprehensive Sex Education: What are the arguments? What is the evidence? AIDS Research Institute University of California, San Francisco. $32 \mathrm{pp}$.

Culp-Ressler, T. (2013).Teen Pregnancy Is Most Common In Rural America Where There May Be More Barriers to Birth Control. New York. 2pp.

DeCoster J. (2006). Testing Group Difference Using T-Test, ANOVA and Nonparametric Measures. University of Alabama, United States of America. 73pp.

Dunor, H. (2015). School based reproductive health education programmes and teenage pregnancy in Mtwara region, Tanzania. Dissertation for the Award of Master of Arts Rural Development, Sokoine University of Agriculture, Morogoro, Tanzania, 99pp

Ewald, T. A. (2008). Perceptions toward contraception among secondary school adolescent girls in Dar es Salaam, Tanzania Muhimbili University of Health and Allied Sciences. [http://hdl.handle.net/123456789/1092] site visited on11/05/2013.

Femina (2013).Midyear Report.FeminaHIP Patel Building, Dar es Saalam, Tanzania 18pp.

Fisseha, G. (2015). Knowledge and Misconception of young women toward sexual transmitted infection and 
condoms use in Northern Ethiopia: cross sectional Study. College of Health science, School of Public health, Mekelle University, Ethiopia. Journal of public health and Epidemiology 7(4): 138 - 144.

Healy, M. (2012). How parents, teens handle talking about sex: In USA TODAY, https://www.usatoday.com/story/news/nation/2012/10/02/parents-teens-sex-talk/ 1606371/ [30/04/2018]

Hussein, A. (2009). The Use of Triangulation in Social Sciences Research: Can Qualitative and Quantitative methods be combined? Mzumbe University, Tanzania. Journal of Comparative Social Work 1: 1 - 12.

Imron, A. (2014). Peer educator and adolescent reproduction health education. Research on humanities and Social Sciences 4(15): 97 - 105.

Kawai, K. (2008).Parents' and teachers' communication about HIV and sex in relation to the timing of sexual initiation among young adolescents in Tanzania. Scandinavian Journal of Public Health 36(8):879-888.

Kirby, D., Laris, B. A. and Lori, R. (2005).Impact os Sex and HIV Education Programs on Sexual Behaviours of Youth in Developing Countries. Youth Research Working Paper No. 2. Family Health International Research Triangle Park, USA. 56pp.

Kanire, G. (2012). Social Science Research Methodology: Concepts, Methods and Computer Applications. GRIN Verlag ISBN 3656329877, 9783656329879. 96 pp

Kessler, C. (2009). PASHA's Contribution to Addressing Teenage Pregnancies in Tanzanian Schools. A brief for dissemination. A short report by Claudia Kessler, SCIH/STI, based on the consultancy report of Regina Goergen, April 2009. SCIH (Swiss Centre for International Health), Basel, Switzerland. http://www.tzdpg.or.tz/fileadmin/documents

/dpg internal/dpg working groups clusters/cluster2/education/3-CoreDocuments/ Teenage_Pregnancy_PASHA09.pdf[19/04/2018]

Knopf A. S., McNealy K R., Al-Khattab H, Carter-Harris L, Marian .O .U, Naanyu V, and Burke Draucker C. (2017) Sexual learning among East African adolescents in the context of generalized HIV epidemics: A systematic qualitative meta-synthesis United State National Library of Medicine. National Institute of Health Vol. 12(3)

Makundi, P. E. (2010). Factors contributing to high rate of teen pregnancy. A study of Mtwara MA. Dissertation for Award of Muhimbili University of Health and Applied Sciences, Dar es Salaam, Tanzania, 51pp.

Mbeba, R. M., Mkuye, M. S., Magembe, G. E., Yotham, L. W., Mellah, O. A. and Mkuwa, B. S. (2012). Barriers to sexual reproductive health services and rights among young people in Mtwara District, Tanzania: a qualitative study. Pan African Medicine 13: 1 - 13.

Minaya, J., Owen-Smith, A. and Herold, J. (2008). The impact of sex education on HIV knowledge and condom use among adolescent females in the Dominican Republic. International Journal of Adolescent Medicine and Health 20(3): 275-282.

Nyakubega, P. (2009).Factors Associated with Adolescent Pregnancies AmongSecondary School Students. A Study Official Publication of the Tanzania Medical Students’ Association, Tanga, Tanzania. 3pp.

Paul-Ebhohimhen, V. A., Poobalan, A. and Van Teijlingen, E. R. (2008). A Systematic reviews of school-based sexual health interventions to prevent STI/HIV in Sub-Saharan Africa. BMC Public Health 8: 1 - 4.

Phetla, G., Busza, J., Hargreaves, J. R., Pronyk, P. M., Kim, J. C., Morison C. L., Warts, C. and Porter J. D. H. (2008). They have opened our mouths. Increasing women's skills and motivation for sexual communication with young people in rural South Africa. AIDS. Education and Prevention 20(6): 504 - 518.

Planned Parenthood (2012). Half of All Teens Feel Uncomfortable Talking to Their Parents About Sex While Only 19 Percent of Parents Feel the Same, New Survey Shows. https://www.plannedparenthood.org/aboutus/newsroom/press-releases/half-all-teens-feel-uncomfortable-talking-their-parents-about-sex-while-only19-percent-parents [20/7/2014\}

Siettou, M. and Sarid, M. (2011). Risk factors of teenage pregnancy. Journal of VinaTouAsklipiou 10(1): 38 - 55. Sunder, S.M. (2007). Research Methods for Business Students. ( ${ }^{\text {rd }}$ Ed), Pearson Education Pte Ltd., India. $203 \mathrm{pp}$.

Thato, R., Jenkins, R. A. and Dusitsin, N. (2008). Effects of the culturally- sensitive comprehensive sex education programme among Thai secondary school students Journal of Advanced Nursing 62(4): 457-469.

Thin Zaw P. P., Liabsuetrakul, T., Htay T. T. and McNeil, E. (2012). Equity of Access to Reproductive Health Services among Youths in Resource Limited Suburban Communities. BMC Research, Myanmar, Asia. 12pp.

Tumbo-Masabo, Z. (1994). Too little too Late. Eds Zubeida Tumbo-Masabo and Rita Liljeström: Chelewa, chelewa : the dilemma of teenage girls. Scandinavian Institute of African Studies, Uppsala, 306pp

Underhill K., Operario, D. and Montgomery, P. (2007). Sexual Abstinence-only Programs for HIV Infection Prevention in High-Income Countries. Systematic Review. University of Oxford, Oxford, London. 12pp.

United Republic of Tanzania (URT) (2010).Tanzania Demographic and Health Survey. National Bureau of Statistics, Dar es Salaam, Tanzania. 69pp.

Warren, C. A. B. (2002). Qualitative Interviewing. In:Handbook of Interview Research.(Editors by Gubrium, J. F. and Holstein, J. A.), Context and Method, Thousand Oaks. 20pp. 
World Health Statistics (2013). World health statistics. [viwww.who.int/gho/world_health_statistics] site visited on $7 / 2 / 2014$.

\section{Hawa Dunor Biography}

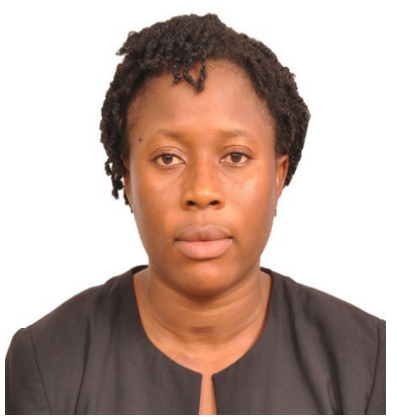

Hawa Dunor holds a Master of Arts Degree (Rural Development) from Sokoine University of Agriculture, United Republic of Tanzania. In addition, Hawa holds a Bachelor of Arts (Sociology) from Cuttington University, Suakoko Bong County. In 2012 Hawa was selected for Class III of the President's Young Professional Program (PYPP), Republic of Liberia where she was assigned to the Ministry of Gender, Children and Social Protection following the appointment, she played a pivotal role in the establishment of the Adolescent Girls Unit then, now the Division at the Ministry of Gender, Children and Social Protection. In March 2018, she was recognized by the Ministry of Gender, Children and Social Protection Republic of Liberia as an Emerging Young Women's Leader during the celebration of the International Women's Day. In addition, Hawa is a 2018 graduate of the Women Lead Institute (WLI) where she earned a Certificate in Women Leadership in Washington D.C. United States of America. Currently, Hawa serves as a Secretary General, of the ECOWAS Young Women Leadership, Liberia Chapter. From 2016 to present, Hawa has served as Director of the Adolescent Girls Division at the Ministry of Gender, Children and Social Protection, the Division is charged with oversight responsibilities of all adolescent girls programs in Liberia. Hawa's interests include human rights especially the rights of children, girls and women. Others are food security for all.

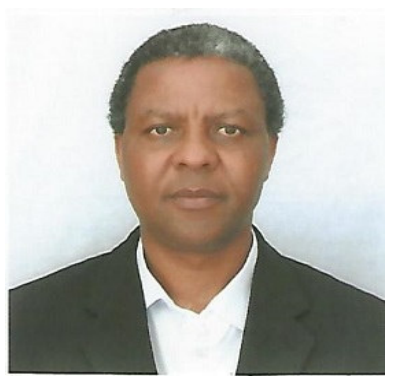

Justin K. Urassa is an Associate Professor, Department of Policy, Planning and Management (DPPM), Campus College of Social Sciences and Humanities (CSSH)-Sokoine University of Agriculture (SUA). Urassa also serves as Chairperson for the DPPM's Policy Dialogues and is the Chief Editor of the East African Journal of Social Sciences and Humanities. Urassa holds a PhD (in Development Studies) and an MSc (Social Research Methods- Development Studies), from the University of Sussex, United Kingdom). Urassa also poses a Postgraduate Diploma in Poverty Analysis for Socioeconomic Security and Development from the Institute of Social Studies-The Hague, Holland in collaboration with the Economic and Social Research Foundation (ESRF)Tanzania and Research on Poverty Alleviation (REPOA)-Dar es Salaam, Tanzania. Justin also holds a Diploma, an MSc and a BSc (Agriculture) from SUA, Tanzania. His research interests cover rural livelihoods and wellbeing, poverty analysis, food security, agricultural and rural development, policy analysis, social development (Education), and governance and development. 